\title{
Supporting Survivors of Public Mass Shootings
}

\author{
Rebecca G. Cowan, $\mathrm{PhD}$ \\ Walden University, Minneapolis, Minnesota, United States \\ (iD) https://orcid.org/0000-0001-5511-435.3 \\ Craig R. Blum, PhD \\ Walden University, Minneapolis, Minnesota, United States \\ (iD) https://orcid.org/0000-0002-0111-0338 \\ G. Mihalyi Szirony, $\mathrm{PhD}$ \\ Walden University, Minneapolis, Minnesota, United States \\ (iD) https://orcid.org/0000-0001-7242-1048
}

\section{Rick Cicchetti, PhD}

Walden University, Minneapolis, Minnesota, United States

(iD) https://orcid.org/0000-0002-7035-2402

Contact: rebecca.cowan@mail.waldenu.edu

\section{Abstract}

Mass casualty incidents, particularly mass shootings, are a serious issue in the United States. These incidents have increased over the past 2 decades, and more than 32 public mass shootings have occurred since 2016, with approximately 12.8 incidents occurring each year. Since 1966, there have been more than 1,202 fatalities and countless injuries due to public mass shooting incidents. Therefore, it is essential that professional counselors are equipped to treat primary, secondary, and tertiary victims of these incidents. The purpose of this article is to examine the current literature on public mass shootings, including psychological consequences, treatment considerations, ethical and legal issues, and cultural factors. Vicarious traumatization and self-care are also explored. Recommendations for training and resources are offered, and implications for professional counselors and counselor trainees are discussed.

Keywords: mass shooting; professional counselors; counselor trainees; disaster mental health

Date Submitted: May 10, 2020 | Date Published: June 23, 2020

\section{Recommended Citation}

Cowan, R. G., Blum, C. R., Szirony, G. M., \& Cicchetti, R. (2020). Supporting survivors of public mass shootings. Journal of Social, Behavioral, and Health Sciences, 14, 169-182. https://doi.org/10.5590/JSBHS.2020.14.1.12

\section{Introduction}

The Congressional Research Service (Krouse \& Richardson, 2015) defined mass killings as "four or more deaths occurring in the same incident” (p. 4). Public mass shootings occur in a variety of settings, such as malls, theaters, concerts, and schools (National Council for Behavioral Health, 2019). They are not necessarily 
motivated by criminal activity, such as an armed robbery (Krouse \& Richardson, 2015) and are not domestic violence (Peterson \& Densley, 2019). In recent years, such incidents have increased in frequency across the nation and are becoming deadlier, with eight of the most fatal mass shootings occurring over the last 5 years (Mother Jones, 2019; Peterson \& Densley, 2019). Overall, there were 82 mass shootings between 1996 and 2015 with frequency doubling between 2011 and 2015 (seven incidents per year) when compared to incidents between 1996 and 2010 (3.3 incidents per year; Callcut et al., 2019). Additionally, 34\% of all mass shootings in the United States have occurred since 2016 (Callcut et al., 2019), including the two deadliest: the Route 91 Harvest Music Festival in Las Vegas, Nevada, in 2017 and the Pulse Nightclub shooting in Orlando, Florida, in 2016 (Peterson \& Densley, 2019). During this time, mass shootings have continued to increase, with 12.8 incidents occurring each year (Callcut et al., 2019).

Peterson and Densley (2019) recently published an open-access database that explored all public mass shooters from 1966 to $2019(n=171)$. They found that $98 \%$ of mass shooters were males with an average age of 33.74 years. These shootings claimed 1,202 lives (Peterson \& Densley, 2019) and injured countless others. Per Brown and Goodin's (2018) research, there is a median of six fatalities per mass shooting, and for school shootings, there is an average of 10.1 fatalities per incident. Peterson and Densley (2019) found $28.1 \%$ of mass shootings occurring since 1966 took place in the workplace, $14.1 \%$ in restaurants/bars, $12.9 \%$ in retail stores, $7.6 \%$ in schools, $6.4 \%$ in places of worship, $5.3 \%$ in universities, and $2.9 \%$ in government buildings.

With the rapid increase of mass shootings occurring within the United States, it is vital that professional counselors are equipped to work with survivors of these acts of violence. However, there are significant gaps in the counseling literature. For instance, a content analysis of three influential counseling journals (The Journal of Counseling and Development, The Journal of Mental Health Counseling, and Counselor Education and Supervision) conducted by Webber et al. (2017) found only 10 articles (0.004\%) published between 1994 and 2014 on mass trauma (disaster, $n=1$; terrorism, $n=7$; war, $n=2$ ), none of which provided guidance on how to support survivors of mass shootings.

Since the conclusion of the Webber et al. (2017) study, a review of the literature identified just two additional articles on mass trauma (Day et al., 2017; Tarvydas et al., 2017) published in The Journal of Counseling and Development and no articles in The Journal of Mental Health Counseling or Counselor Education and Supervision. Therefore, the purpose of the present article was to examine what is currently known in the limited scholarly literature on the psychological consequences of public mass shootings and to offer treatment alternatives. Based on the empirical literature and the authors' years of combined experience in primary and secondary trauma, implications for professional counselors and counselor trainees are discussed. For example, the primary author has treated survivors of three mass shooting incidents. After the Route 91 Harvest Festival mass shooting, this author provided psychological first aid and support to survivors and family members of the deceased. She worked directly with survivors within the local hospitals, community memorials, and the Family Assistance Center, where survivors came to secure various resources. When responding to the Parkland, Florida, school shooting at Marjory Stoneman Douglas High School, this author ran support groups for survivors and their parents and supported survivors and community members at memorials. When responding to the Virginia Beach Municipal Center mass shooting, this author attended memorial services and provided support groups for survivors. She has also had the opportunity to work with survivors long-term within her private practice. 
Cowan et al., 2020

\section{Psychological Consequences}

\section{Survivors}

Due to the nature of mass shootings, there are often survivors who endure physical and psychological injuries as a result of experiencing a mass casualty incident (MCI; U.S. Department of Veteran Affairs, 2020). Survivors of mass shootings are comprised of every religion, race, and socioeconomic background (Novotney, 2018). Mass shootings can be considered human-made, separating them from natural or hybrid disasters (a combination of the two). When compared to those who have experienced natural disasters, survivors of human-made disasters, such as public mass shootings, are at a higher risk of experiencing psychological distress (Novotney, 2018). Their sense of safety and trust are severely compromised, and they often report a broad range of emotions that can change and evolve, including anger, sadness, fear, helplessness, and frustration (U.S. Department of Veteran Affairs, 2020). As a result, survivors of mass violence often report depression, anxiety, sleep issues, somatic complaints, cognitive issues, complicated grief, and posttraumatic stress disorder (PTSD; Substance Abuse and Mental Health Services Administration [SAMHSA], 2017; U.S. Department of Veteran Affairs, 2019, 2020).

Studies have shown between $40 \%$ and 95\% of direct victims develop PTSD after a mass shooting (Goldmann \& Galea, 2014; Littleton et al., 2011). Survivors who report a history of trauma and mental health issues have an even higher risk of developing traumatic stress reactions (Levers \& Hyatt-Burkhart, 2019; U.S. Department of Veteran Affairs, 2019). Other individual risk factors include low socioeconomic status, being aged 40-60, being female, or being a member of an ethnic minority group. Exposure to media may also worsen the survivor's ability to cope and may increase the risk of developing PTSD due to exposure to graphic images and videos (SAMHSA, 2017; Thompson et al., 2019). Social factors such as lack of support, limited access to resources, and differences in the ability to "move on" from the MCI may also increase the risk of developing psychopathology (U.S. Department of Veteran Affairs, 2019). Finally, community factors associated with worse mental health outcomes after a mass shooting include poor community cohesion, which often threatens resiliency and recovery in a reciprocal cycle of entropy. The myriad physical and psychological problems associated with MCIs demand the marshaling of services and interventions that can help all involved. These are addressed later in this article, after reviewing the impact on those beyond the immediate survivor.

\section{Wider Community}

Mass shootings not only impact those who were present for the event (primary victims) but also the communities in which the incident occurred and beyond (secondary and tertiary victims; National Mass Violence Victimization Resource Center, 2018). Between $5 \%$ and $10 \%$ of individuals within a community where mass violence has occurred will develop PTSD (U.S. Department of Veteran Affairs, 2019), although that number could be higher. The community has been described as a "covictim" of this type of violence, as many organizations, schools, and businesses are impacted by mass shootings (Rowhani-Rahbar et al., 2019). These incidents typically lead to significant social disruption, which can ultimately cause loss of community cohesion and complicate healing (Crandall et al., 2013).

Beyond direct community impacts, approximately $33 \%$ of adults in the United States fear becoming a victim of a mass shooting, which prevents them from attending certain events or going to public places such as the mall, community events, movie theaters, and schools (American Psychological Association [APA], 2019).

More than $79 \%$ of U.S. adults report feeling stressed about mass shootings. Additionally, the incessant media coverage of mass shootings has been found to put individuals in every community across the United States at higher risk for secondary traumatization (SAMHSA, 2017). As with a stone thrown in a pond, the rippling effect of MCIs engulf those beyond the immediate survivor and also require attention. 
Cowan et al., 2020

\section{First and Second Responders}

First responders, such as police officers, paramedics, and firefighters, who respond to MCIs, are at significant risk for developing PTSD, even more so in human-made MCIs, such as mass shootings (Golden et al., 2013). They are directly exposed to deceased victims, numerous injured survivors, and are often tasked with delivering difficult news to victims' family members. Chopko and colleagues (2018) reviewed the impacts on responders to MCIs. They explored the challenges these individuals have in dealing with the trauma itself, carrying out their official duties that need to balance support for victims while addressing the crime and the criminal(s), and then returning to their civilian lives.

Counselors frequently serve as second responders (Hope, 2014) and report to the scene or an alternate location after first responders have secured the site of the incident. Counselors are not immune to PTSD and vicarious traumatization (VT) when working with survivors of mass shootings (American Counseling Association [ACA], n.d.-d; Pearlman \& Mac Ian, 1995). It is not uncommon for counselors who have responded to a traumatic event such as an MCI to experience VT (McCann \& Pearlman, 1990), which is often interchangeably referred to as secondary traumatic stress (STS; ACA, n.d.-d) or compassion fatigue. The primary traumatic event is not necessarily the only source of emotional damage, as the deleterious effects could come from secondary or even tertiary forces. When working with survivors of mass shootings, counselors are often indirectly exposed to traumatic content related to death, brutality, horror, and destruction, which can lead to a variety of adverse emotional effects. Counselors must be aware that this is not a sign of "incompetence or weakness" (Quitangon \& Evces, 2015, p. 39) as "no one who sees a disaster is untouched by it" (p. 77); however, these effects should be addressed as quickly as possible. As with first responders, these professionals balance many roles during and after such events (Trippany et al., 2004). Cloaked in a veil of deniability, VT does not always signal its presence until it has done its damage. It is vital to help these responders themselves, and this will also allow them to continue to serve victims and the community during the initial and subsequent phases of the impact of MCIs.

\section{Implications for Professional Counselors}

\section{Treatment Considerations}

The U.S. Department of Veteran Affairs' (2018) National Center for PTSD suggested a postevent phase structure (impact, immediate, intermediate, and long term) that can help counselors organize individuals' reactions and the type of assistance that might be most appropriate. Shootings tend to have a shorter impact phase than other disasters such as floods, fires, and tornados because the survivor is typically able to return home. The subsequent phases have an associated focus with the immediate phase being related to rescue, intermediate with recovery, and long-term to reconstruction. Similarly, SAMHSA (2017) identified three aftermath phases: acute, intermediate, and long term.

\section{Immediate or acute phase}

People in the immediate or acute phase (SAMHSA, 2017; U.S. Department of Veteran Affairs, 2018) need information and assistance on how to access resources to make it through the immediate hours, days, and weeks. Survivors in this stage often exhibit signs of shock and denial (Novotney, 2018) and modalities such as psychological first aid (Bisson et al., 2007) including the normalization of emotional responses (ACA, n.d.-c) such as fear, anxiety, and sadness have proven to help reduce distress (Novotney, 2018). Triage and assessment should be used to identify clients who require immediate attention (SAMHSA, 2016), as expeditious intervention can help mitigate distress (National Institute of Mental Health, 2002). During this phase, counselors can use brief interventions and teach survivors practical stress management techniques 
(ACA, n.d.-b), such as progressive muscle relaxation, diaphragmatic breathing, and writing exercises, as these can be used to help survivors better manage distress.

During the immediate or acute phase, counselors may find it helpful to network with other counselors and mental health professionals in the community by setting up email distribution lists or private social media pages where resources can be readily shared. Communication is critical and connecting survivors to community resources, support groups, and other supportive services is vital (Kar \& Cochran, 2019; Novotney, 2018). Merely knowing what services are available may reduce anxiety, even if the survivor chooses not to seek out services or supports during this phase. Additionally, counselors may find it beneficial to explore the social supports the survivor had in place preincident, such as ministers, friends, therapists, and family members, and work to help to connect or reconnect them to these individuals.

Counselors may find survivors will not readily seek traditional counseling services during the immediate or acute phase as collective healing is often occurring in the community (Novotney, 2018). Therefore, it might be helpful for counselors to support survivors beyond the counseling office by attending memorials, services, and other community gatherings and events. Attending these events should not be a time for client recruitment, but rather a way to provide support to survivors, their family members, and the overall community. Connecting with community stakeholders is also imperative, as these individuals can often help connect survivors in need of assistance to counselors and other supportive services. Finally, in terms of community support, counselors might offer psychoeducational and time-limited support groups to allow affected community members a safe place to process. Similarly, psychological debriefing (ACA, n.d.-a) and Critical Incident Stress Management (Golden et al., 2013; Guenthner, 2012) groups may be held for first and second responders.

\section{Intermediate phase}

The intermediate phase is where more traditional forms of counseling and psychotherapy are frequently needed (U.S. Department of Veteran Affairs, 2018; SAMHSA, 2017). Not everyone that experiences (directly or indirectly) a mass shooting will develop PTSD or related disorders (Miron et al., 2014), but experiencing such events most certainly qualifies for the first part of the Diagnostic and Statistical Manual of Mental Disorders (fifth edition; American Psychiatric Association, 2013) criteria for such problems, namely, direct experience, witnessing, connection to family or friends experiencing such events, and so on.

APA (2017) recently developed a Clinical Practice Guideline on PTSD in Adults that recommends using "cognitive behavioral therapy (CBT), cognitive processing therapy (CPT), cognitive therapy (CT), and prolonged exposure therapy (PE)" (p. ii) as well as "brief eclectic psychotherapy (BEP), eye movement desensitization and reprocessing (EMDR), and narrative exposure therapy (NET)” (p. ii). There are other points made relative to other approaches (including some medications) for which they had "insufficient evidence." However, Norcross and Wampold (2019) disagreed with institutionalizing such approaches. They noted that "the therapy relationship, treatment adaptations, and individual therapist effects, all of which independently account for patient improvement more than the particular treatment method" (p. 391). Above all, no matter what modality is chosen, the counselor should be sure to provide trauma-informed care (Novotney, 2018) rooted in empirical research.

\section{Long-term phase}

Counselors will find that during the long-term phase, most people will not require significant or ongoing clinical services, although there can be periods of exacerbation around anniversary dates or when new episodes of violence occur in the world (SAMHSA, 2017; U.S. Department of Veteran Affairs, 2018). Some survivors even experience a time of posttraumatic growth during this phase (Novotney, 2018) and report positive life changes as a result of enduring the traumatic experience (Calhoun \& Tedeschi, 2000). Yet, some 
individuals will find this to be a challenging time, as ineffective coping strategies are no longer effective or become problematic (e.g., use of substances become an issue).

Those with more chronic histories of trauma will often require longer and more complex treatment (Orcutt et al., 2014). Paying close attention to the survivor's response during the acute phase can help to provide counselors with a better picture of how survivors might be affected in the long-term phase (Rowhani-Rahbar et al., 2019). For instance, survivors who show greater symptoms earlier in the recovery process and do not benefit from interventions in the acute phase will likely need to be connected with longer term supports. Quickly identifying and connecting these individuals with long-term services is ideal. During the long-term phase, counselors should also continue to provide psychoeducation to the general community about trauma and what to expect during the long-term recovery process (Novotney, 2018) and can accomplish this by partnering with news outlets, holding information sessions, or distributing community newsletters.

During the long-term phase, counselors should also be aware that there could be an influx of first responders seeking supportive services as their trauma often goes unrecognized during the initial stages of recovery (Golden et al., 2012). Additionally, some may avoid treatment until symptoms become unbearable. For this reason, throughout the long-term phase, it is ideal to offer support groups to first responders periodically. If initial groups provided during the acute phase of recovery were not well attended, do not assume that this indicates that first responders were not impacted or do not have an interest in engaging in supportive services in this current phase.

\section{Cultural Factors and Considerations}

The grieving process is rooted in culture and considered a critical life event (Cicchetti et al., 2016; Walter, 2010), including various traditions, norms, and values. The role of mourning, what to do with the dead, and how to handle emotions is often influenced by culture. Therefore, counselors are required to deliver culturally competent services and be sensitive to these cultural differences when working with survivors of mass shootings and family members of the deceased. When it comes to grief, individuals in the United States tend to be on the "individualist end of the spectrum" (Walter, 2010, p. 4); however, this may not be the case for all involved. Cultural awareness is critical. Counselors should be aware of the client's cultural identity as well as the overall culture of the community. For instance, the grieving process after the school shooting in Parkland, which has one of the most densely concentrated Jewish populations in Florida (Glassman, 2016), looked very different than the expression of grief and mourning after the First Baptist Church shooting in Sutherland Springs, Texas (Hanna \& Yan, 2017). Describing these various cultural factors and considerations is beyond the scope of this article; however, please see Cacciatore and DeFrain (2015) for more information. When in doubt, counselors should always ask the survivor about their cultural identity and preferences and, above all, value diversity and respect differences.

Language barriers should also be considered when working in communities that have experienced a mass shooting. When a community is comprised of a diverse ethnic makeup, such as in El Paso, Texas (83\% Hispanic; U.S. Census Bureau, 2019), where the 2019 mass shooting at Walmart occurred (Attanasio et al., 2019) information about supportive services and community events should be translated into the predominant language. The immigration status of survivors and community members should also be considered, as this could be a potential barrier to seeking supportive services. For instance, several undocumented immigrants were survivors of the Route 91 Harvest Festival shooting in Las Vegas and had to pursue special visas (i.e., U nonimmigrant visas) to avoid deportation (Bekker, 2017). If survivors and community members fear repercussions for seeking services, their needs will go unmet and psychological distress may ultimately persist. Creating safe, confidential spaces for all is vital. 
Cultural differences also exist among U.S. adults regarding their fears about becoming a potential victim of a mass shooting and their ability to cope with those fears (APA, 2019). A study conducted by the APA (2019) found that Hispanic adults (32\%) reported more significant stress related to the possibility of a mass shooting when compared to non-Hispanic adults (15\%). Additionally, this study found that $44 \%$ of Hispanic adults, $43 \%$ of Black adults, and $30 \%$ of White adults reported that they felt unprepared to deal with this stress. Black adults report higher rates of perceived victimization as $60 \%$ of this population said they felt like they could be killed, or someone they know could be killed in a mass shooting, when compared to $50 \%$ of Hispanic adults and $41 \%$ of White adults. Counselors need to be aware of the differential experiences of trauma among various groups, as well as sensitive and trained to respond to their different experiences and ways of coping with such events, to be able to provide the necessary outreach and provision of services to help them.

\section{Ethical and Legal Implications}

Counselors who respond to mass shooting incidents must abide by the standards put forth in the ACA (2014) code of ethics and should understand how to navigate ethical decision-making (James \& Gilliland, 2017). If counselors are volunteering or working with an organization or relief agency (e.g., the American Red Cross [ARC]), they should also be cognizant of any ethical guidelines put in place by these entities. Particular attention should be given to informed consent procedures and confidentiality, as these can differ in emergency situations (James \& Gilliland, 2017). Additionally, when counselors are attending public gatherings and memorials, cellphone use, social media, and photographs should be limited. Respect for confidentiality is within the ethical domain of counselors and must be remembered in every setting.

Counselors should also be mindful of the potential legal implications of practicing outside of their state in the event they respond to a mass shooting in another location (Hodge et al., 2010). For instance, when a state of emergency is declared, licensure reciprocity is recognized, but only throughout the duration of the emergency. During the response, counselors must also be aware of the laws and regulations governing the practice of counseling within the state where they are practicing when treating survivors. Due to the complexity of this issue, counselors should seek out opportunities for consultation (Tarvydas et al., 2017) with counselors who are licensed within the state as well as supervisors. For a more in-depth discussion of this topic, please refer to Tarvydas et al. (2017).

\section{Vicarious Trauma}

Renshaw et al. (2011) documented the concept of STS in a population of individuals related to military service members and veterans who experienced psychological distress. They noted the link between combat-related PTSD and psychological stress that had carried over into spouses of military members. Similarly, counselors may absorb and take on the fear and mistrust of their traumatized clients, which may cause them to experience symptoms that mirror PTSD, such as intrusive thoughts, hypervigilance, hyperarousal, and avoidance (Quitangon \& Evces, 2015). Counselors might also experience changes in their view of themselves, others, and the world (McCann \& Pearlman, 1990). In a study exploring VT, Pearlman and Mac Ian (1995) examined trauma therapists $(n=188)$, based on psychological well-being and found that therapists with a history of trauma and less than 2 years of counseling experience demonstrated higher levels of psychological difficulty. The results of this study suggested that greater levels of training in trauma therapy may help increase awareness, which in return may minimize or diffuse the duration and extent of the trauma (Bacharach et al., 2008; Pearlman \& Mac Ian, 1995).

Learning how to handle such factors and to create diversions for more stressful aspects of the job can help counselors prevent VT/STS as well as increase productivity. Self-care should begin at the very early stages of 
an MCI response as prevention of VT/STS instead of intervention is preferable (Quintangon \& Evces, 2015). Ultimately, counselors should limit the number of survivors to whom they agree to provide therapeutic services, reach out to colleagues and clinical supervisors when assistance or support is needed, and vary their client panel as much as possible. Counselors should take frequent breaks, limit their exposure to media coverage about the MCI, and take other preventative steps (Quintangon \& Evces, 2015; SAMHSA, 2017; Thompson et al., 2019; Trippany et al., 2004). Additionally, counselors should check in on colleagues often and bring any signs of VT/STS to their attention. Measures such as the Self-Care Assessment Scale (Saakvitne \& Pearlman, 1996) and the Secondary Traumatic Stress Scale (Bride et al., 2004) may assist with the assessment of self-care and counselor distress while working with survivors of MCIs, such as mass shootings.

\section{Self-Care}

Calming strategies, as seen in various mindfulness approaches, such as meditation, yoga, Reiki, massage therapy, and Tai Chi, may help serve as a defense against such threats to counselor well-being (ARC, 2010; Quintangon \& Evces, 2015). Stemming from the work of Kabat-Zinn (2003), the construct of mindfulness has been applied to the world of counseling (Fulton, 2016), and plays a key role in the interference as well as prevention of VT/STS (Quintangon \& Evces, 2015). For example, a study by Davidson et al. (2003) found alterations in brain and immune function during periods of mindfulness meditation. Rod (2015) also published on the positive effects of mindfulness, supporting the need for quiet time. Other approaches that have been proven effective in reducing VT/STS include engaging in leisure activities, peer consultation, connecting with family members and friends, and mental health counseling (ARC, 2010; Quintangon \& Evces, 2015). These tools are useful for all survivors and responders alike (Chopko et al., 2018).

\section{Training and Resources}

Topics related to trauma and crisis are included in three out of the eight core Council for Accreditation of Counseling and Related Educational Programs (2016) areas. Per the standards, upon graduating from a Council for Accreditation of Counseling and Related Educational Programs-accredited program, counselors should have an understanding of how crisis, disaster, and trauma impact individuals across the lifespan and should have knowledge of crisis intervention and trauma-informed strategies such as psychological first aid. Outside of counselor education programs, there are multiple resources available to counselors that might be useful when responding to MCIs. For instance, the Federal Emergency Management Agency's (2019) Emergency Management Institute has several free online training and resources pertaining to psychological first aid, crisis counseling, and emergency management. SAMHSA (2011) offers a free disaster kit with a variety of resources that can be easily downloaded and printed. Additionally, SAMHSA offers several webinars and training through the Disaster Technical Assistance Center. The Federal Bureau of Investigation (n.d.) also provides a toolkit containing several resources for active shooter incidents, and the ACA offers a repository of trauma and disaster mental health resources on their website (ACA, 2019). Finally, the Office for Victims of Crime (OVC; 2015) provides multiple resources for professionals responding to mass violence incidents.

If counselors are interested in more advanced training opportunities, the National Organization for Victim's Assistance (NOVA) provides a Crisis Responder Credentialing Program (NCRCP; 2019) for a fee and the OVC Training and Technical Assistance Center (2019) offers a free National Victim Assistance Academy. Counselors can also complete disaster training through ARC (2019) and can become Disaster Mental Health volunteers through that same organization. To learn more about VT, the Vicarious Trauma Institute (2015) offers several trainings on VT for helping professionals and the Green Cross Academy of Traumatology (2019) provides certification in compassion fatigue therapy. These resources, and the other ideas reviewed in this 
article, serve to prepare counselors for the seemingly ever-increasing traumatic events in our communities and across the country.

\section{Future Research and Direction}

Because mass shooting incidents are steadily increasing, additional research studies must be developed to address how counselors can adequately prepare for these incidents. As a way to explore counselors' competence regarding mass shooting incidents, a qualitative study may be warranted. Specifically, this study could be conducted with counselors who have recently worked with survivors of mass shootings. This exploration could highlight content that needs to be integrated into counselor education or continuing education programs as well as other training implications. Additionally, survey research could be conducted with this same population, as this would allow for a larger sample size to be targeted. This research could potentially focus on factors such as the counselor's theoretical perspective, experience level, years in the field, education level, as well as their ability to support survivors. Additional research exploring VT when working with survivors of mass shootings is also warranted, and how risk of VT can be mitigated.

More literature is also needed specifically concerning effective treatment and intervention with survivors of mass shootings as well as their family members and the general community. This research could further explore how survivors of mass shootings navigate the post-event phase structure put forth by the U.S. Department of Veteran Affairs' (2018) National Center for PTSD and SAMHSA (2017) and how counselors might be better able to meet their needs in each of these phases. Specifically, longitudinal research focusing on the long-term phase of survivor recovery could be explored to determine specific supports needed in this phase. Finally, research is also needed on how the general community is impacted after mass shootings to determine best practices when working with this population.

\section{Conclusion}

Public mass shootings are increasing in frequency and becoming deadlier (Mother Jones, 2019; Peterson \& Densley, 2019). Counselors often assist as second responders to these events and may find themselves providing ongoing mental health services to survivors, community members, and first and second responders. However, there is very little, if any, professional counseling literature guiding this work. As survivors of mass shootings turn to counselors during these times of need, it is our duty to provide ethical and culturally sensitive mental health care grounded in empirical research. Our hope is that this article will assist counselors with this critical work.

\section{References}

American Counseling Association (ACA). (2014). ACA code of ethics. https://www.counseling.org/resources/aca-code-of-ethics.pdf

American Counseling Association (ACA). (2019). Trauma and disaster mental health. https://www.counseling.org/knowledge-center/mental-health-resources/trauma-disaster

American Counseling Association (ACA). (n.d.-a). Debriefing. https://www.counseling.org/docs/traumadisaster/fact-sheet-11---debriefing.pdf?sfvrsn=e762cd50_2

American Counseling Association (ACA). (n.d.-b). Helping survivors with stress management skills. https://www.counseling.org/docs/trauma-disaster/fact-sheet-13---helping-survivors-with-stressmanagement-skills.pdf?sfvrsn $=625 \mathrm{~b} 433 \mathrm{a} 2$ 
American Counseling Association (ACA). (n.d.-c). Post-trauma/Disaster stress. https://www.counseling.org/docs/trauma-disaster/fact-sheet-1---post-trauma-disasterstress.pdf?sfvrsn $=24 \mathrm{fdc} 8 \mathrm{cg} \_2$

American Counseling Association (ACA). (n.d.-d). Vicarious trauma. https://www.counseling.org/docs/trauma-disaster/fact-sheet-9---vicarioustrauma.pdf?sfvrsn=fofo3a27 2

American Psychiatric Association. (2013). Diagnostic and statistical manual of mental disorders (5 ${ }^{\text {th }}$ ed.). https://doi.org/10.1176/appi.books.9780890425596

American Psychological Association (APA). (2017). Clinical practice guideline for the treatment of PTSD. https://www.apa.org/ptsd-guideline/ptsd.pdf

American Psychological Association (APA). (2019). One-third of U.S. adults say fear of mass shootings prevents them from going to certain places or events. https://www.apa.org/news/press/releases/2019/o8/fear-mass-shooting

American Red Cross (ARC). (2010). Disaster services: Coping with disaster. https://intranet.redcross.org/content/dam/redcross/documents/our services/DisasterCycleServices $\angle$ descapabilities/individual_clientservices/disaster_mental_health/ReturnHomeDisasterAssignBrochure. pdf

American Red Cross (ARC). (2019). Disaster training. https://www.redcross.org/take-a-class/disastertraining

Attanasio, C., Bleiberg, J., \& Weber, P. J. (2019). Police: El Paso shooting suspect said he targeted Mexicans. AP News. https://apnews.com/456c0154218a4d378e2fb36cd40b709d

Bacharach, S. B., Bamberger, P. A., \& Doveh, E. (2008). Firefighters, critical incidents, and drinking to cope: The adequacy of unit-level performance resources as a source of vulnerability and protection. Journal of Applied Psychology, 93, 155-169. https://doi.org/10.1037/0021-9010.93.1.155

Bekker, J. (2017, October 22). Immigrants at Las Vegas festival during shooting apply for visas. Las Vegas Review Journal. https://www.reviewjournal.com/crime/shootings/immigrants-at-las-vegas-festivalduring-shooting-apply-for-visas/

Bisson, J. I., Brayne, M., Ochberg, F., \& Everly, G. S. (2007). Early psychological intervention following traumatic events. American Journal of Psychiatry, 164, 1016-1019. https://doi.org/10.1176/ajp.2007.164.7.1016

Bride, B., Robinson, M. R., Yegidis, B., \& Figley, C. R. (2004). Development and validation of the Secondary Traumatic Stress Scale. Research on Social Work Practice, 14, 27-35. https://doi.org/10.1177/1049731503254106

Brown, J., \& Goodin, A. J. (2018). Mass casualty shooting venues, types of firearms, and age of perpetrators in the United States, 1982-2018. American Journal of Public Health, 108(10), 1385-1387. https://doi.org/10.2105/AJPH.2018.304584

Cacciatore, J., \& DeFrain, J. (Eds.). (2015). The world of bereavement: Cultural perspectives on death in families. Springer International.

Calhoun, L. G., \& Tedeschi, R. G. (2000). Early posttraumatic interventions: Facilitating possibilities for growth. In J. M. Violanti, D. Paton, \& C. Dunning (Eds.), Posttraumatic stress intervention: Challenges, issues and perspectives (pp. 135-152). Charles C. Thomas. 
Callcut, R. A., Robles, A. M. , Kornblith, L. Z., Plevin, R. E. \& Mell, M. W. (2019). Effect of mass shootings on gun sales: A 20-year perspective. Journal of Trauma and Acute Care Surgery, 87(3), 531-540. https://doi.org/10.1097/TA.0000000000002399

Chopko, B. A., Papazoglou, K., \& Schwartz, R. C. (2018). Mindfulness-based psychotherapy approaches for first responders: from research to clinical practice. The American Journal of Psychotherapy, 71, 5564. https://doi.org/10.1176/appi.psychotherapy.20180015

Cicchetti, R.J., McArthur, L., Szirony, G.M., \& Blum, C.R. (2016). Perceived competency in grief counseling: Implications for counselor education. Journal of Social, Behavioral, and Health Sciences, 10(1), 3-17. https://doi.org/10.5590/JSBHS.2016.10.1.0

Council for Accreditation of Counseling and Related Educational Programs. (2016). 2016 CACREP standards. http://www.cacrep.org/wp-content/uploads/2017/08/2016-Standards-with-citations.pdf

Crandall, W. R., Parnell, J. A., \& Spillan, J. E. (2013). Crisis management: Leading in the new strategy landscape (2nd ed.). Sage.

Davidson, R. J., Kabat-Zinn, J., Schumacher, J., Rosenkranz, M., Muller, D., Santorelli, S. (2003). Alterations in brain and immune function produced by mindfulness mediation. Psychosomatic Medicine, 65(4), 564-570. https://doi.org/10.1097/01.psy.0000077505.67574.e3

Day, K. W., Lawson, G., \& Burge, P. (2017). Clinicians' experiences of shared trauma after the shootings at Virginia Tech. Journal of Counseling and Development, 95(3), 269-278.

https://doi.org/10.1002/jcad.12141

Federal Bureau of Investigation. (n.d.). Active shooter resources. https://www.fbi.gov/about/partnerships/office-of-partner-engagement/active-shooter-resources

Federal Emergency Management Agency. (2019). Emergency Management Institute. https://training.fema.gov/emi.aspx

Fulton, C., (2016). Mindfulness, self-compassion, and counselor characteristics and session variables. Journal of Mental Health Counseling, 38(4), 360-374. https://doi.org/10.17744/mehc.38.4.06

Glassman, M. (2016). Broward Jewish population has declined, but still largest in Florida. https://www.sunsentinel.com/florida-jewish-journal/news/broward/fl-jjbs-demography-1123-20161121-story.html

Golden, L. L., Jones, R. T., Donlon, K. (2013). Delayed treatment seeking following the April 16th shootings at Virginia Tech: Impact on a first responder. Clinical Case Studies, 13(5), 391-404. https://doi.org/10.1177/1534650113512174

Goldmann, E., \& Galea, S. (2014). Mental health consequences of disasters. Annual Review of Public Health, 35, 169-183. https://doi.org/10.1146/annurev-publhealth-032013-1824.35

Green Cross Academy of Traumatology. (2019). Training and CE schedule. https://greencross.org/training-ce/

Guenthner, D. H. (2012). Emergency and crisis management: Critical incident stress management for first responders and business organizations. Journal of Business Continuity \& Emergency Planning, 5(4), $298-315$.

Hanna, J., \& Yan, H. (2017). Sutherland Springs church shooting: What we know. https://www.cnn.com/2017/11/05/us/texas-church-shooting-what-we-know/index.html

Hodge, J. G., Jr, Rutkow, L., \& Corcoran, A. J. (2010). Mental and behavioral health legal preparedness in major emergencies. Public Health Reports, 125(5), 759-762. https://doi.org/10.1177/0033354491012500519 
Hope, M. K. (2014). The P.A.C.E. method: Conflict resolution for first responders: Fire/EMS edition. Pax Pugna.

James, R. K., \& Gilliland, B. E. (2017). Crisis intervention strategies. (8th ed.). Cengage Learning.

Kabat-Zinn (2003). Mindfulness-based interventions in context: Past, present, and future. Clinical Psychology: Science and Practice, 10(2), 144-156.

https://psycnet.apa.org/doi/10.1093/clipsy/bpg016

Kar, B., \& Cochran, D. M. (2019). Risk communication and community resilience. Routledge.

Krouse, W. J., \& Richardson, D. J. (2015). Mass murder with firearms: Incidents and victims, 1999-2013. The Congressional Research Service. https://fas.org/sgp/crs/misc/R44126.pdf

Levers, L. L., \& Hyatt-Burkhart, D. (2019). Clinical mental health counseling: Practicing in integrated systems of care. Springer.

Littleton, H., Kumpula, M., \& Orcutt, H. (2011). Posttraumatic symptoms following a campus mass shooting: The role of psychosocial resource loss, Violence Victims, 26(4), 461-476. https://doi.org/10.1891/0886-6708.26.4.461

McCann, L., \& Pearlman, L. (1990). Vicarious traumatization: A framework for understanding the psychological effects of working with victims. Journal of Traumatic Stress, 3(1), 131-149. https://psycnet.apa.org/doi/10.1007/BFoog75140

Miron, L. R., Orcutt, H. K., \& Kumpala, M. J. (2014). Differential predictors of transient stress versus posttraumatic stress disorder: Evaluating the risk following targeted mass violence. Behavior Therapy, 45(6), 791-805. https://doi.org/10.1016/j.beth.2014.07.005

Mother Jones. (2019). Mass shootings in America: The unavoidable facts. https://www.motherjones.com/crime-justice/2019/08/mass-shootings-in-america-the-unavoidablefacts/

National Council for Behavioral Health. (2019). Mass violence in America. https://www.thenationalcouncil.org/wp-content/uploads/2019/08/Mass-Violence-in-America 8-619.pdf

National Institute of Mental Health. (2002). Mental health and mass violence: Evidence-based early intervention for victims/survivors of mass violence. A workshop to reach consensus on best practice. U.S. Government Printing Office.

National Mass Violence Victimization Resource Center. (2018). Supporting resilience and recovery in the community. https://www.nmvvrc.org/Community/SupportingCommunityResilience

National Organization for Victim's Assistance. (2019). NOVA CredNational Crisis Responder Credentialing Program. https://www.trynova.org/crisis-response-program/credentialing-programs/

Norcross, J. C., \& Wampold, B. E. (2019). Relationship and responsiveness in the psychological treatment of trauma: The tragedy of the APA Clinical Practice Guidelines. Psychotherapy, 56(3), 391-399. https://psycnet.apa.org/doi/10.1037/pstoo00228

Novotney, A. (2018). What happens to the survivors: Long-term outcomes for survivors of mass shootings are improved with the help of community connections and continuing access to mental health support. https://www.apa.org/monitor/2018/og/survivors

Office for Victims of Crime (OVC). (2015). Helping victims of mass violence and terrorism. https://www.ovc.gov/pubs/mvt-toolkit/ 
Office for Victims of Crime (OVC) Training and Technical Assistance Center. (2019). National Victim Assistance Academy. https://www.ovcttac.gov/views/TrainingMaterials/dspNVAA.cfm

Orcutt, H. K., Bonanno, G. A., Hannan, S. M., \& Miron, L. R. (2014). Prospective trajectories of posttraumatic stress in college woman following a campus mass shooting. Journal of Traumatic Stress, 27(3), 249256. https://doi.org/10.1002/jts.21914

Pearlman, L. A., \& Mac Ian, P. S. (1995). Vicarious traumatization: An empirical study of the effects of trauma work on trauma therapists. Professional Psychology: Research and Practice, 26(6), 558-565. https://psycnet.apa.org/doi/10.1037/0735-7028.26.6.558

Peterson, J., \& Densley, J. (2019). The Violence Project mass shooter database. https://www.theviolenceproject.org

Quitangon, G., \& Evces, M. R. (Eds.). (2015). Vicarious trauma and disaster mental health: Understanding risks and promoting resilience. Routledge.

Renshaw, K. D., Allen, E. S., Rhoades, G. K., Blais, R. K., Markman, H. J., \& Stanley, S. M. (2011). Distress in spouses of service members with symptoms of combat-related PTSD: Secondary traumatic stress or general psychological distress? Journal of Family Psychology, 25(4), 461-469.

https://psycnet.apa.org/doi/10.1037/a0023994

Rod, K. (2015). Observing the effects of mindfulness-based meditation on anxiety and depression in chronic pain patients. International Journal of Psychology and Behavioral Sciences, 5(4), 143-147. https://doi.org/10.5923/j.ijpbs.20150504.01

Rowhani-Rahbar, A., Zatzick, D. F., Rivara, F. P. (2019). Long-lasting consequences of gun violence and mass shootings. JAMA, 321(18), 1765-1766. https://doi.org/10.1001/jama.2019.5063

Saakvitne, K. W., \& Pearlman, L. A. (1996). Transforming the pain: A workbook on vicarious traumatization. Norton.

Substance Abuse and Mental Health Services Administration (SAMHSA). (2011). SAMHSA's disaster kit. https://store.samhsa.gov/product/SAMHSA-s-Disaster-Kit/SMA11-DISASTER

Substance Abuse and Mental Health Services Administration (SAMHSA). (2016). Disaster technical assistance center supplemental research bulletin mass violence and behavioral health . https://www.samhsa.gov/sites/default/files/programs campaigns/dtac/srb-communityapproaches.pdf

Substance Abuse and Mental Health Services Administration (SAMHSA). (2017). Disaster technical assistance center supplemental research bulletin mass violence and behavioral health . https://www.samhsa.gov/sites/default/files/dtac/srb-mass-violence-behavioral-health.pdf

Tarvydas, V. M., Levers L. L., \& Teahen, P. R. (2017). Ethical guidelines for mass trauma and complex humanitarian emergencies. Journal of Counseling and Development, 95(3), 260-268. https://psycnet.apa.org/doi/10.1002/jcad.12140

Thompson, R. R., Jones, N. M., Holman, E. A., Silver, R. C. (2019). Media exposure to mass violence events can fuel a cycle of distress. Science Advances, 5(4), 1-6. https://doi.org/10.1126/sciadv.aav3502

Trippany, R. L., Kress, V. E., \& Wilcoxon, S. A. (2004). Preventing vicarious trauma: What counselors should know when working with trauma survivors. Journal of Counseling and Development, 82(1), 31-37. http://dx.doi.org/10.1002/j.1556-6678.2004.tbo0283.x

Vicarious Trauma Institute. (2015). Helping the world's heroes reveal, release, reconnect. http://vicarioustrauma.com/ 
U.S. Census Bureau. (2019). QuickFacts: El Paso County, Texas. https://www.census.gov/quickfacts/elpasocountytexas

U.S. Department of Veteran Affairs. (2018). PTSD: National center for PTSD: Reactions following disaster and mass violence. https://www.ptsd.va.gov/professional/treat/type/disaster reaction phases.asp

U.S. Department of Veteran Affairs. (2019). Risk and resilience factors after disaster and mass violence. https://www.ptsd.va.gov/professional/treat/type/disaster_risk resilience.asp

U.S. Department of Veteran Affairs. (2020). What to expect in the wake of mass violence. https://www.ptsd.va.gov/understand/types/mass violence help.asp

Walter, T. (2010) Grief and culture: A checklist. Bereavement Care, 29(2), 5-9. https://doi.org/10.1080/02682621003707431

Webber, J. M., Kitzinger, R., Runte, J. K., Smith, C. M., \& Mascari, J. B. (2017). Traumatology trends: A content analysis of three counseling journals from 1994 to 2014. Journal of Counseling \& Development, 95(3), 249-259. https://doi.org/10.1002/jcad.12139 issues. JSBHS articles include peer-reviewed research reports, brief resports, comprehensive literature reviews, books reviews, and student research. 